\title{
CANAL FUTURA E OS GRUPOS COMUNITÁRIOS: uma análise das interações midiatizadas
}

\author{
Rosana Cabral Zucolo ${ }^{1}$
}

\begin{abstract}
Resumo: Este artigo discorre sobre a experiência de interação entre o Canal Futura e entidades de ação comunitária que fazem parte de seu campo de articulação e mobilização no social. Analisa as processualidades desencadeadas em torno da implementação do Projeto Maleta Futura: ação que integra as estratégias do canal para a distribuição de seus conteúdos e os de seus parceiros, junto aos grupos sociais de atuação comunitária - no caso, a TV OVO (Oficina de Vídeo Oeste) e o Grupo Ecológico Guardiões da Vida, duas ONGs sediadas nas cidades de Santa Maria e Passo Fundo, no Rio Grande do Sul. O Canal Futura integra as Organizações Globo como um projeto social da Fundação Roberto Marinho, e se caracteriza por uma experimentalidade que permite situá-lo nos espaços de transição da televisão na contemporaneidade. Ao analisar tais processualidades, verificase que as diferentes estratégias e operações provocaram afetações de parte a parte, gerando circuitos comunicacionais não previstos e colocando em circulação novos códigos no quadro das interações comunicativas estabelecidas entre os agentes participantes no cotidiano das práticas sociais e midiáticas. Tal análise é parte da pesquisa de doutoramento que examinou a construção de um dispositivo interacional indicativo de uma experiência singular inserida no cenário complexo das dinâmicas relacionais entre mídia e sociedade, e capaz de fornecer elementos para a problematização dos fenômenos comunicacionais decorrentes do processo de midiatização.
\end{abstract}

Palavras-chave: Televisão, comunidades, dispositivo, interação, midiatização.

\begin{abstract}
This article discusses the experience of interaction between Canal Futura and community action agencies that are part of your field of articulation and social mobilisation. Analyzes procedurals triggered around the implementation of Maleta Futura Project: action that integrates the strategies of the channel for the distribution of its content and its partners, with social groups of community action - in this case, the OVO TV (Video Workshop west) and the Ecological Group Guardians of Life, two NGOs based in the cities of Santa Maria and Passo Fundo, Rio Grande do Sul. The Canal Futura integrates Globo as a social project of the Roberto Marinho Foundation, and is characterized by a experimentally that allows to place it on television transition in contemporary spaces. By analysing such procedurals, it appears that the different strategies and operations have resulted for either party affectations, generating unanticipated communication circuits and putting into circulation new codes in the context of communicative interactions established between the players taking part in the daily social and media practices. This analysis is part of the doctoral research examined the construction of an indicative interactional device a unique experience inserted in the complex scenario of relational dynamics between media and society, and able to provide input to the questioning of the communicational phenomena resulting from mediatization process.
\end{abstract}

Keywords: Television, communities, device, interaction, mediatization.

\section{Introdução}

A reflexão sobre as processualidades interacionais desencadeadas durante a implementação do Projeto Maleta Futura pelas equipes do Canal Futura - integrante das Organizações Globo e da Fundação Roberto Marinho (BR) -, junto a grupos gaúchos de ação

${ }^{1}$ Professora no curso de Jornalismo do Centro Universitário Franciscano (Unifra), Doutora em Ciências da Comunicação pela Universidade do Vale do Rio dos Sinos (Unisinos), Mestre em Educação pela Universidade Federal de Santa Maria (UFSM), e graduada em Jornalismo também pela UFSM. E-mail: rosana.zucolo@gmail.com. 
comunitária, a Oficina de Vídeo Oeste (TV OVO) e o Grupo Ecológico Guardiões da Vida (GEGV), selecionados em seu campo de articulação e mobilização social, remete a uma experiência singular inserida no cenário complexo das dinâmicas relacionais entre mídia e sociedade, e capaz de fornecer elementos para a problematização dos fenômenos comunicacionais decorrentes do processo de midiatização.

Envolve não só a percepção do funcionamento da mídia como um novo ambiente de informação e comunicação, mas também a discussão acerca das mudanças significativas na paisagem da televisão contemporânea com destaque para as continuidades, readaptações e estratégias que permitem a coexistência e a complementaridade entre o passado e presente dessa mídia. Assim, a análise aqui desenvolvida se dá com base na observação das interações e dos processos que regulam as situações de comunicação entre os diferentes agentes envolvido no processo analisado, enfocando as relações que tais processos organizam na sua singularidade, uma vez que tanto a mídia quanto os receptores e suas mediações se movem em formações múltiplas.

Para fazer inferências sobre essas dinâmicas, observam-se no contexto caracterizado pelo perfil dos dois conjuntos de agentes os processos que demarcaram a constituição de vínculos e as apropriações no espaço de negociação entre a produção, a oferta, a recepção e a circulação de um dos principais projetos em que a interação vem se realizando: o Projeto Maleta Futura.

É sobre essas processualidades e suas consequências, tanto na instância midiática quanto nas práticas sociais comunitárias, que esta análise busca refletir. Cabe ressaltar que tal reflexão é um dos resultados da tese de doutoramento defendida no ano de 2014 junto ao programa de Pós-graduação em Comunicação na Universidade do Vale do Rio dos Sinos (Unisinos), em São Leopoldo, RS, Brasil.

\section{Lógicas interacionais e agentes sociais num contexto de midiatização}

A mediação dos meios de comunicação e o desenvolvimento acelerado das tecnologias desde a segunda metade do século XX geram procedimentos que tem ampliado largamente as possibilidades de interação midiatizada, constituindo um cenário complexo de processos comunicacionais capazes de colocar em circulação uma variedade de produtos e processos múltiplos, características de uma sociedade em midiatização. 
As interações entre a lógica midiática marcada por estratégias e operações tecnodiscursivas através das quais a mídia passa a atuar como referente dos modos diversificados que a sociedade aciona para poder interagir; e a lógica da vida cotidiana, habitualmente caracterizada pela profusão de falas, gestos, coisas, gentes em movimentos de apropriações e ressignificações que se dão de modo imprevisível e mesmo incontrolável, modificando as pretensões estabelecidas na origem; evidenciam um contexto de interação e transformação da sociedade no qual as técnicas e os padrões de produção da mídia tradicional também se veem afetados (grifo meu).

Toma-se de Rodrigues a noção de que

a percepção que temos hoje do mundo tornou-se dependente de complexos e permanentes dispositivos de mediatização que marcam o ritmo da nossa vida quotidiana, sobrepondo-se cada vez mais não à nossa percepção imediata do mundo, mas também aos ritmos do funcionamento das instituições que formam os quadros da nossa experiência individual e coletiva. (RODRIGUES, 2010, p. 169).

Em tal contexto, as relações sociais passam a ser regidas por protocolos que se apoiam na lógica da mídia, ao mesmo tempo em que regulam, emprestam materialidade a um novo espaço social de interação. A instância midiática gera uma transformação multidimensional que afeta textos, práticas e relações sociais e emerge enquanto processo interacional de referência (Braga, 2006). Isto é, passa a atuar como referente dos modos diversificados que a sociedade aciona para poder interagir. Uma vez instaurados, tais processos passam a afetar a constituição da própria instância midiática, gerando novos modos de interação.

Concordando com Braga (2011), as mudanças decorrentes destes processos de interação midiatizada modificam continuamente o perfil, os sentidos e os modos de operar dos campos sociais, e as formas de interação entre eles e a sociedade. No momento em que são organizados novos processos interacionais, os antigos vínculos pessoais e comunitários são reconfigurados, emergem novos espaços de interação, saberes e práticas são deslocados de seus lugares canônicos, colocando em circulação, de modo experimental, sentidos outros que alteram os modos de ação dos campos sociais e as operações entre eles.

Atualmente, a midiatização das interações - sejam elas interpessoais ou com a sociedade - se refletem em circuitos comunicacionais que atravessam os campos sociais, intensificando a circulação simbólica e gerando afetações que atingem as matrizes socialmente por eles produzidas. E isso se dá através de múltiplos componentes que podem 
ser observados a partir do que Braga (2011) denomina de "dispositivos interacionais" e referem aos modos de interagir que a sociedade experimenta historicamente em cada momento ou processo social. É dizer de um sistema de relações operando entre os distintos componentes do processo, que se articulam com base em padrões já existentes para que a interação ocorra.

À medida que tais dispositivos são "modulados pelos contextos e processos institucionais específicos em cujo ambiente ou referência se desenvolvem" (BRAGA, 2012: p.06), comportam e dispõem sobre um conjunto de regras, determinações, regularidades que marcam discursividades em uma determinada matriz social, preparam níveis de circulação, lógicas de negociações e modos de inserção dos atores sociais, "modelizando" o funcionamento do comunicacional. As diferenças e as defasagens processuais, não apenas fazem o circuito funcionar, como apontam as especificidades do processo comunicativo.

Braga $(2000$, p.18) já alertava também para a probabilidade de que nenhum processo ou produto de interação social mediatizada consiga ser totalmente autocirculante. Para que possa circular, dependem componentes externos que devem se colocar "em interação com processos e organizações internas do tipo de produto em causa, enquanto sistema crítico". Este, para ter viabilizada a sua circulação na sociedade, atendendo as expectativas, necessidades e desejos dos usuários, depende de estruturas organizativas operadas pela própria sociedade. Assim, a interatividade mediatizada remete à competência de interagir com os produtos (e através destes, com a sociedade) que envolve interpretação, seleções, percursos, avaliações, entre outros. "Essa competência não é dada, se constrói junto com a construção de estruturas, por aproximações sucessivas, em constante reelaboração histórica" (ibidem). Por sua vez, tal competência pode gerar (ou não) credibilidade aos processos de interação, sugerindo consistência, regularidades, continuidades, estabilidade.

\subsection{O Canal Futura e a Articulação e Mobilização Comunitária}

O Canal Futura integra as Organizações Globo como um projeto da Fundação Roberto Marinho e se desenvolve a partir de um modelo peculiar de sustentabilidade apoiado em parcerias como setor privado, mantenedor da programação e das ações sociais de mobilização via distintos projetos. Se enuncia enquanto "um canal privado de interesse público, dedicado à educação", com "o compromisso social de ampliar as possibilidades de mobilização e 
participação das camadas D e E, para as quais dirige preferencialmente a sua programação". (FRM/Canal Futura, 2010, p. 12)

O Canal Futura opera em espaços tradicionalmente não televisivos através de uma instância mediadora, a Articulação e Mobilização Comunitária que atua junto aos grupos de ação comunitária e de movimentos sociais, e de onde emanam sugestões/produções de conteúdos para o canal, alterando também a relação entre produtor/usuário. Desse modo, apropria-se de uma dinâmica de outro campo que não o televisual, interagindo com ele de forma quase experimental, através da produção de novas processualidades de contatos e interações com a comunidade. Gera assim novos circuitos e modos de circular seus produtos seriais.

Tal instância é central na operacionalidade do Canal, sendo, ao mesmo tempo, estratégia e organização. Trata-se de um setor operacional, cuja gerência tem o mesmo status e poder deliberativo das demais gerencias. Atua em 17 estados brasileiros, e opera com estratégias e abordagens singulares na constituição de parcerias com organizações que desenvolvem projetos próprios ou em conjunto. Desse modo, se constitui num componente diferencial e pouco habitual em uma estrutura de grande mídia, e que corresponde à necessidade do canal de dispor, internamente, de grupos com competências interacionais para se relacionar com comunidades de caráter popular. Trata-se da necessidade de disponibilizar mediadores que assegurem o contato entre a instância midiática e a comunitária, e através dos quais a confiança no canal pode ser gerada, mantida ou reforçada.

Denominados de "educadores sociais", os mediadores tem papel estratégico e vital ao modelo de gestão, uma vez que são os responsáveis pela articulação com os movimentos e grupos comunitários. Isto exige que as equipes de articulação e mobilização tenham um perfil específico capaz de realizar mediações entre o Canal e o ambiente dos grupos sociais e, em geral, são indicados e/ou escolhidos entre profissionais que possuem em sua trajetória de vida, vínculos ou vivências com grupos que desenvolvem ações sociais diversas.

O canal opera sem sede física nas bases regionais, através das equipes de mobilização que atuam na identificação, articulação e mobilização dos grupos comunitários das respectivas regiões. Hoje, a região sul tem uma mobilizadora sediada em Porto Alegre para atender os três estados. A região nordeste é atendida por três mobilizadores sediados em Salvador (BA), João Pessoa (PB) e Recife (PE) para atuarem, também, nos estados do Maranhão, Alagoas, Sergipe e Rio Grande do Norte. Na região Norte, dois mobilizadores 
estão sediados em Belém (PA) e Manaus (AM), com ações no estado do Tocantins. Outros três respondem pela região sudeste com base nas capitais São Paulo e Rio de Janeiro, e cobrem Minas Gerais, Espírito Santo e Mato Grosso do Sul. Na sede central, quatro coordenadoras respondem por projetos específicos, além da gerência geral do setor.

O contato (rotinas) entre a sede central e os mobilizadores ocorre por meio das ferramentas tecnológicas de comunicação (telefones, e-mail, skype) ou, ainda, em reuniões presenciais agendadas com antecedência.

No tocante ao contato das equipes com os grupos comunitários, os mobilizadores evidenciam que "nos processos vale tudo para contatar: fone, skype, email, facebook... sinal de fumaça. Usamos aquilo que a pessoa/ instituição possui, acha mais fácil." (op.cit) ${ }^{2}$

Os deslocamentos dos mobilizadores às regiões dos grupos comunitários se dão mediante agendamento, conforme o projeto em questão. Por ocasião das implementações e formação, não raro, eles permanecem pelo período alternado de uma semana no local sede dos grupos envolvidos e o fato das equipes serem exíguas, faz com que frequentemente se desloquem de um território a outro.

Uma vez identificados grupos comunitários "potenciais" aos objetivos do CF, as equipes de mobilização articulam os contatos e iniciam o trabalho junto a eles de preparação para o uso dos conteúdos (projetos e ações de recepção) ou de produção conteúdos ou, ainda, de proposição de conteúdos. A rigor, o trabalho da mobilização comunitária envolve pesquisa, capacitação, acompanhamento e avaliação mediante o monitoramento e análise dos resultados alcançados, além de ampliar o alcance da iniciativa através de oficinas, para capacitar multiplicadores.

O foco temático se dá na elaboração e apoio de projetos sociais para a formação com ênfase à questão do audiovisual, desenvolvimento sustentável, direitos humanos, qualidade de vida, saúde e segurança alimentar e nutricional. E projetos voltados para o atendimento da juventude, com o desenvolvimento de ações voltadas para a valorização da identidade juvenil, atuando fortemente na conscientização e no enfrentamento à violência, especialmente o extermínio da juventude negra, empreendedorismo e formação profissional para atividades locais, e o incentivo à formação audiovisual para a produção em parceria com o Canal.

\footnotetext{
${ }^{2}$ Respostas coletadas por questionário online junto aos mobilizadores do CF.
} 
A ação de contato com os grupos comunitários ocorre no formato de parceria colaborativa, sem que se assumam compromissos de ordem formal ou institucional, à exceção dos trabalhos de produção de conteúdo.

\subsection{Práticas sociais comunitárias: a Oficina de Vídeo Oeste e o Grupo Ecológico Guardiões da Vida}

Sem entrar na discussão teórica que envolve a revisão das noções de comunidade/comunitário, defende-se que a apreensão do sentido de tais conceitos se dánas construções emergentes dos grupos investigados, nascidos num contexto histórico favorável às ações coletivas de caráter social. Assim, trabalha-se o sentido acionado pela via da experiência, da vida cotidiana marcada predominantemente por práticas colaborativas e atitudes mobilizadoras, singulares, que remetem a distintos modos de interação social, com fortes demarcações espaciais, territoriais.

O Grupo Ecológico Guardiões da Vida (GEGV) é uma ONG, fundada em 1999, na cidade de Passo Fundo, RS, e se volta à problemática ambiental no município e na região. Tem forte atuação local e participa em fóruns e mobilizações em instâncias decisórias das temáticas ambientais como a Comissão de Políticas de Desenvolvimento Sustentável (CPDS) e a Agenda 21 Nacional. Se tornou uma das principais referências do Canal Futura enquanto modelo de ações bem sucedidas nos usos da Maleta Futura.

No ano de 2005 a ONG, a Embrapa, a Coordenadoria Estadual de Educação e o Canal estabeleceram parceria no projeto de implantação de hortas comunitárias em setes escolas públicas na região da cidade de Passo Fundo, denominado 'Semeando o Caminho para o Futuro', apontado pelos mobilizadores como um dos projetos de melhores resultados. O Canal Futura fazia a cobertura jornalística de tal processo, o que deu início à parceria com a ONG.

Já a Oficina de Vídeo Oeste ou TV OVO, como é conhecida, é uma associação sem fins lucrativos, caracterizada como meio de comunicação alternativo com foco na formação e na produção audiovisual. Consolidou-se como espaço de atuação social de base empírica, voltado para a formação de jovens de baixa renda através de projetos de capacitação para a produção audiovisual. Ao incorporar jovens da periferia, os torna próprios realizadores e estimula-os a mostrarem a realidade das comunidades onde vivem. Atuatambém associado a grupos de cooperativismo local e a projetos de caráter cultural e de memória coletiva na área 
do audiovisual. A TV OVO tem sido parceira do Canal Futura também na produção de conteúdos.

Tais grupos empreendem, cada um ao seu modo, a difusão pública de suas experiências comunitárias. Se como ativistas, como formadores, a depender do quanto estiverem motivados pelos interesses em jogo em diferentes momentos, e suas atuações são comumente balizada por conceitos teóricos de diversas procedências em torno das suas causas e tais concepções são refletidas nos conceitos de senso comum da linguagem usual, tornandose mais inteligíveis e de fácil apreensão (Gusmão, 2012). É também possível observar a tendência crescente em dominar um determinado universo conceitual que fundamente suas práticas, legitimando-as. Isto ocorre na medida em que os grupos e seus membros passam a circular em contextos outros com exigências comunicacionais e interacionais mais complexas, que exigem e provocam mudanças internas substanciais.

Visualiza-se nos processos comunitários destes grupos uma comunicação que se dá em torno de questões específicas de interesses comuns propagadas, usualmente, através de contatos "boca a boca", em interações "face a face". Elas são promovidas e promotoras de debates dos quais resultam negociações e decisões processadas de modo interpessoal e em apropriações e usos dirigidos de tecnologias que se sobrepõem, independentes de uma análise da sua eficácia. Neles, a tecnologia e/ou a técnica não são consideradas pontos de partidas no fluxo das comunicações e a ênfase dos grupos se volta, prioritariamente, à dimensão relacional do convívio social com foco em ações de mobilização.

Colocado a serviço de uma causa específica, o uso das técnicas e tecnologias da comunicação se evidencia tanto pela produção e emprego do simples e velho panfleto convocador de reuniões, quanto pelo acesso às ferramentas da internet em busca de visibilidade ou de ampliação do alcance convocatório/reivindicatório. São espaços de usos simultâneos, sobrepostos; de adesões circunstanciais e flexíveis em termos de continuidade; de ações voluntárias, na maioria das vezes consensuais e, em sua maior parte, não monitoradas nos seus resultados. É possível dizer, ainda, de ações politicamente dirigidas que também visam influenciar as formulações de políticas públicas.

Nessa linha de pensamento, os grupos comunitários em questão desenvolvem uma percepção singular do que seja o comunitário. Tais percepções estão atreladas às circunstâncias das suas constituições e das operações desencadeadas na direção dos objetivos a serem alcançados, cabendo ressaltar não se tratar de práticas planejadas e projetadas, mas 
sim de "movimentos" capazes de agenciar processos múltiplos na articulação de um projeto coletivo.

Ambos os grupos têm sua representação simbólica mediada pela cultura midiática e possuem a clara percepção de que o aparato da mídia pode potencializar suas ações e visibilizar sua causa, independente do posicionamento ideológico de cada parte.

É desse modo que na interação com o Canal Futura, os grupos vislumbram também a possibilidade de experimentação e de reinvenção dos usos do audiovisual e do televisivo propriamente dito, num processo que sugere estar implícita uma perspectiva de empoderamento e busca de novas práticas interlocutivas. Carregam suas realidades e seus enquadramentos, inventando o seu modo de fazer, e não se limitando apenas àquilo que o canal oferece. Têm seus próprios projetos e as suas constituições comunicativas no uso do projeto em questão.

\section{A Maleta Futura: produto e estratégia midiática}

A Maleta Futura é um dos principais projetos do Canal, colocado em circulação pela via da Articulação e Mobilização comunitária e gestado durante o ano de 2006 em parceria com o setor de Conteúdo. Surgiu como proposta para solucionar o hiato que se gerou no espaço entre a produção /distribuição/redistribuição dos conteúdos do Canal, devido ao não acompanhamento do percurso dos programas e demais produtos midiáticos que saíam do canal pela via da articulação e da mobilização comunitária. Não havia como monitorar, efetivamente, a circulação dos conteúdos.

Considerado uma estratégia do canal para além da TV, o projeto Maleta Futura se caracteriza como ação transversal, de mobilização comunitária, com foco na implementação, distribuição e redistribuição de conteúdos do Futura e de seus parceiros. Desde o lançamento do projeto seis maletas foram implementadas - Toda Beleza (2006), Meio Ambiente (2008), Democracia (2010), Saúde (2011), Infância (2013) e a Maleta Por quê Pobreza?(2014). Ele reúne a seleção de parte da produção televisiva do Canal Futura de acordo com recortes temáticos e abrangentes, alinhado com suas políticas internas e voltado para o trabalho junto das entidades que compõem as redes articuladas por ele em todo o Brasil.

Do ponto de vista midiático, integra tanto a proposta de desenvolvimento e circulação de conteúdos, quanto às estratégias das ações de mobilização comunitária do Canal ao 
envolver diferentes grupos comunitários em torno de temáticas específicas e metodologias experimentais. Sua estratégia de contato prevê o convite às 'instituições de referência'3, identificadas pelas equipes de Articulação e Mobilização, a fim de que a Maleta Futura seja agregada às ações já realizadas por aquelas em seu cotidiano. Em tal cenário, ela chega aos grupos como um elemento fortalecedor dos conceitos e das ações já trabalhadas pelas instituições/organizações, com a proposta de provocar reflexão sobre a realidade local e incentivar iniciativas que busquem a transformação social.

Uma vez definido o tema e a pesquisa do material que irá compor o acervo de cada maleta, passa-se à produção, isto é, ao processo de pesquisa de materiais com parceiros nos territórios, escolha dos programas, elaboração de conteúdo do caderno de atividades e à confecção da maleta produto.

A maleta possui o formato de uma mala similar a dos caixeiros viajantes, customizada com o logotipo e imagens coloridas que remetem aos conteúdos temáticos do Canal. Cada maleta é customizada conforme o tema da edição vigente. Tal formato foi escolhido por associar o projeto ao caráter itinerante do caixeiro viajante que vai a todos os lugares, mesmo aqueles inimagináveis, e também para sugerir a possibilidade dos usuários incluírem nela novos materiais.

Cada maleta traz uma compilação temática dos programas mais recentes e abrangentes do canal, reunida a materiais impressos e inéditos elaborados por equipes próprias em parceria com consultores externos. Inclui, ainda, produtos pedagógicos, entre lúdicos e didáticos, bem como materiais temáticos de organizações e instituições parceiras, constituindo um kit que comporta uma maleta customizada conforme os temas abordados e na qual são inseridos os produtos selecionados. Além da maleta completa, há a "maletinha" (maleta básica), uma versão simplificada do kit criada com o objetivo de garantir a circulação dos conteúdos a um maior número de envolvidos sem onerar o orçamento do projeto. Ela é entregue à instituição de referência, ou cabeça de rede no jargão televisivo, que assume responsabilidade de "replicar" a Maleta. Para tanto, recebe a Maleta Futura completa e indica seus parceiros para receberem as “maletinhas” ou Maletas Básicas.

No momento em que aderem ao projeto, as instituições assinam um termo de cooperação técnica com o Canal e têm, durante dois anos, o apoio das equipes de mobilização

\footnotetext{
${ }^{3}$ Terminologia utilizada pelo CF para identificar seus parceiros. Percebeu-se que nos documentos do CF e na fala de suas equipes, o emprego do termo oscila conforme o seu contexto de origem, sendo correlato às expressões 'parceiro principal', 'parceiro cabeça de rede', 'parceiro institucional'.
} 
comunitária para a implementação das Maletas. Isto se dá através de visitas de acompanhamento aos parceiros envolvidos, da realização de grupos focais ou de reuniões de socialização das atividades com outras instituições participantes e consultores. Durante esse período as equipes de Articulação e Mobilização Comunitária assessoram os grupos, e também asseguram a participação do canal nas agendas estratégicas das organizações parceiras. Realizam atividades de formação sobre a utilização do acervo, sugestões metodológicas sobre como trabalhar temas e jogos disponíveis na maleta, monitoram os planos traçados para verificar se serão necessárias adequações, orientam sobre a alimentação online do sistema e, ainda, atuam na avaliação final.

O projeto é colocado em circulação com suas estratégias e normas já definidas na instância da produção mas, uma vez entregue aos grupos comunitários, a Maleta fica sujeita aos usos que estes fazem dos seus conteúdos. Uma vez no processo e de posse das maletas, os modos de uso e de circulação dos conteúdos, sua seleção e distribuição na rede de parceiros de cada grupo comunitário estão na dependência dos fluxos instituídos pelos interesses e estratégias destes, e não necessariamente na observância das metodologias sugeridas pelo Canal. Os relatos acerca destes usos ao canal dependem da disponibilidade e da instituição de uma prática de registro em cada grupo. Neste aspecto, observa-se que o monitoramento e a retroalimentação das informações se dão, na maior parte das vezes, através do contato direto com as equipes de mobilização, seja presencial ou telefônico, apesar de o canal ter implantado um sistema de banco de dados online para o acompanhamento do emprego da Maleta.

Em tais operações não há garantias, o que permite pensar que a atuação do midiático, a partir da proposta do canal, torna-se altamente volátil e, exatamente por isto, se caracteriza por uma celeridade peculiar na busca da superação das supostas "falhas" que emergem destas tentativas. Conforme pesquisas internas, apenas $25 \%$ das informações completas sobre as atividades desenvolvidas com o projeto retornam. Ao mesmo tempo, este não retorno e mesmo a lentidão da postagem dos dados têm gerado o aperfeiçoamento do sistema e a busca de novos modelos de avaliação.

Segundo a compilação dos dados informados pelos parceiros “cabeças de rede", $75 \%$ das informações relativas às ações realizadas com a maleta estão incompletas. Do total das informações retornadas, somente $25 \%$ permitem uma visão global das ações realizadas e do número de participantes. No entanto, tais dados mensuráveis não necessariamente são fidedignos. Nos relatos orais deste estudo, há indicações de que os números podem ser 
"adequados" na instância dos parceiros comunitários de modo a atender as exigências do projeto $^{4}$. Tal atitude sinaliza, ao mesmo tempo, a dificuldade de parte dos parceiros comunitários em entender o preenchimento do formulário cedido pelo canal, como também a intencionalidade decorrente da compreensão do que realmente importa dentro da lógica de oferta da instância midiática.

\section{Interações midiatizadas: considerações finais}

Enquanto parte do sistema televisivo, é na atividade de mobilização comunitária que o Canal Futura se reconhece, enunciando os seus termos de referência e a sua identidade enquanto mídia televisiva: "projeto social de comunicação (...) capaz de transformar o social pela tela da televisão”.

Entre suas operações está o projeto Maleta Futura e seus conteúdos enquanto estratégia de comunicabilidade do Canal, reconhecendo-se nessa processualidade um conjunto de regras referidas, explicitamente ou não, para que se realize processos comunicacionais do ponto de vista da recepção/produção. Assim, ainda que o projeto permita a inclusão de novos produtos para a circulação, é a instância da produção quem determina os conteúdos na tentativa de assegurar o controle do processo de produção dos sentidos. Por conta disso, o projeto Maleta se mantém praticamente inalterado enquanto modelo, com poucas referências no tocante à inclusão das reivindicações dos parceiros comunitários. Seu formato tem se mantido e é um dos projetos mais "estáveis" dentro da oferta do canal. Nesse sentido, opera como matriz organizativa, obedecendo regularidades ditadas pelo quadro de referências para a sua produção. Tal regularidade se faz presente nos materiais do canal e indica processos mistos de aprendizagem e socialização. Neles as tentativas bem sucedidas são incorporadas ao modelo viável, isto é, o que funciona bem se torna um modelo e gera um padrão. Ao mesmo tempo, significa que quem quiser entrar no sistema do canal, terá que operar dentro desse modelo.

Por outro lado, enquanto as operações do Canal, mediadas pelos mobilizadores, evidenciam que as regularidades da chamada televisão educativa implicam lentidão quando ela busca ser pedagógica - porque aposta na linearidade da aprendizagem e no regramento hierárquico dos usos -, os movimentos comunitários se mostram ágeis na reelaboração da proposta e das estratégias, movidos pelas urgências de suas práticas. Nessa operacionalidade,

\footnotetext{
${ }^{4}$ Informação verbal, obtida junto aos grupos comunitários analisados.
} 
criam-se circuitos comunicacionais outros, não previstos pelo polo da produção, e que retornam ao canal na forma de relatos de experiências, podendo modificar, em parte, a própria produção. Claro que há graus de escuta, bem como variações complexas no acolhimento da mesma. Nesse sentido, o potencial propriamente pedagógico da Maleta está exatamente nas múltiplas possibilidades de relações que se estabelecem a partir do seu uso. A percepção dessas dinâmicas produtoras de sentidos, evidencia, pensando com Braga (2012), que "é da reverberação mútua entre "falas" e "escutas", de parte a parte, que se alimentam os processos interacionais em sua produção de sentido". Tais observações resultam de episódios distintos nas dinâmicas interacionais em tentativas de acertos e produção.

Assim, as processualidades analisadas indicam uma mobilidade tal, de parte a parte, que as estratégias evidenciam na circulação social dos sentidos, um espaço de reconhecimento e de desvios produzidos pelas dinâmicas de apropriação.

Nesse cenário se configuram processos tentativos cuja continuidade permite que sejam montados padrões e regras que são geradas a partir das estratégias em ação.

\section{Referências}

BRAGA, José Luiz. A sociedade enfrenta sua mídia - dispositivos sociais de crítica mediática. São Paulo, Editora Paulus, 2006.

Dispositivos interacionais. GT Epistemologia da Comunicação. XX Compós, UFRGS, Porto Alegre, 2011.

\section{Qual teoria - qual problema. Seminário PROCAD "Crítica} Epistemológica", reunião de Goiânia, 2011a.

Circuitos versus campos sociais. In: Janotti J., Jacks N., Mattos, M.A. Mediações e Midiatização, Livro Compós, Salvador, Edufba, 2012.

CANAL FUTURA. Almanaque das Redes Sociais Futura. Rio de Janeiro, Fundação Roberto Marinho/Canal Futura, 2010.

GUSMÃO, Luis de. O fetichismo do conceito. Limites do conhecimento teórico na investigação social. Rio de Janeiro, Topbooks, 2012.

RODRIGUES, Adriano Duarte. Comunicação e cultura. A experiência cultural na era da

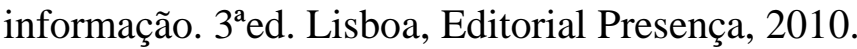


ZUCOLO, Rosana C. Dispositivos interacionais e interações midiatizadas: um estudo sobre a implementação do Projeto Maleta Futura, Canal Futura, em Santa Maria e Passo Fundo/RS. Tese de doutorado, Programa de Pós-graduação em Comunicação, Unisinos, São Leopoldo, 2014. 